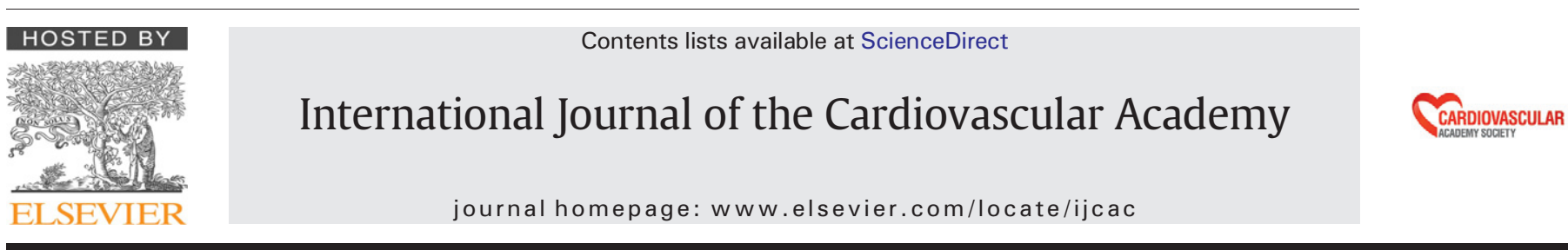

Short communication

\title{
Acute myocardial infarction with single coronary artery
}

\author{
S. Varol, B. Ayca, G. Kum, E.B. Karaayvaz, T. Ayyıldız, E. Okuyan
}

Bagcilar Training and Research Hospital, Department of Cardiology, Turkey

\section{A R T I C L E I N F O}

\section{Article history:}

Received 5 May 2015

Received in revised form 4 August 2015

Accepted 5 August 2015

Available online 8 September 2015

\section{Keywords:}

Myocardial

Infarction

Single

Coronary

Artery and aVL, 2-5 mm of ST depression on leads II, III, aVF and V1-V6 were evident (Fig. 1). The diagnosis was high lateral myocardial infarction. The results of biochemical laboratory tests are summarized in Table 1.

Tigacrelor $180 \mathrm{mg}$, acetylsalicylic acid $300 \mathrm{mg}$ and heparin $100 \mathrm{IU} / \mathrm{Kg}$ IV bolus were administered and the patient was urgently referred to the cardiac catheterization laboratory. A 6 French Left Judkins diagnostic catheter failed to engage the left main coronary ostium at the level of left sinus of Valsalva. Contrast injection with right Amplatz catheter showed a single coronary originated from the right coronary cusp. The left anterior descending (LAD) and circumflex (Cx) artery originated from the right coronary ostium separately. LAD was rudimentary and subtotal discrete lesion was present on the proximal segment of circumflex artery (Fig. 2). After crossing the lesion with 0.014 -inch guide wire, a $2.5 \times 10 \mathrm{~mm}$ balloon was inflated at $8 \mathrm{~atm}$. Then, a $3.0 \times 16 \mathrm{~mm}$ TaxusLiberte Drug Eluting Stent (DES) was implanted at $12 \mathrm{~atm}$. Immediately after stent implantation, localized small linear dissections were observed on the proximal edge of the stented segment. A Taxus Liberte $3.0 \times 15 \mathrm{~mm}$ DES were implanted on the dissected segment and successfully sealed (Fig. 3). Following the procedure, the patient was transferred to Coronary care unit (CCU). Angina and hemodynamic symptoms were resolved. Blood test results were in the normal range except troponin, which was $0.043 \mathrm{ng} / \mathrm{mL}$ on admission (Fig. 1). Echocardiogram revealed posterolateral hypokinesis with left ejection fraction of $45 \%$. Follow-up cardiac enzymes showed early peaking values (Table 2). The patient was discharged on day 4.

\section{Discussion}

Single coronary artery is a term that is used to describe left and right coronary arteries originated from one coronary ostium. It was first angiographically described in 1967 in two patients. ${ }^{1,2}$ Though conus artery can originate from separate ostium, it is ignored, and the term "single coronary artery" has been used. Prevalence is $0.02-0.04 \%$ and is nearly equal for the right and left coronary arteries. ${ }^{1-4}$ Based on the Lipton classification, single coronary artery types can be grouped into three classes. Class I contains coronaries with normal course. For example, the right coronary (R-I) is at the normal location and continues as circumflex artery after the posterolateral branch and left anterior descending after the posterior descending branch. At the left-sided single coronary (L-II), left anterior descending is normal and the circumflex artery terminally continues as the right coronary. In Class II, the single left or right coronary artery gives rise to a truncus that has a transverse course on the base of the heart to yield contralateral coronary arteries. This can be subclassified as A, B, or P according to the course of truncus. 


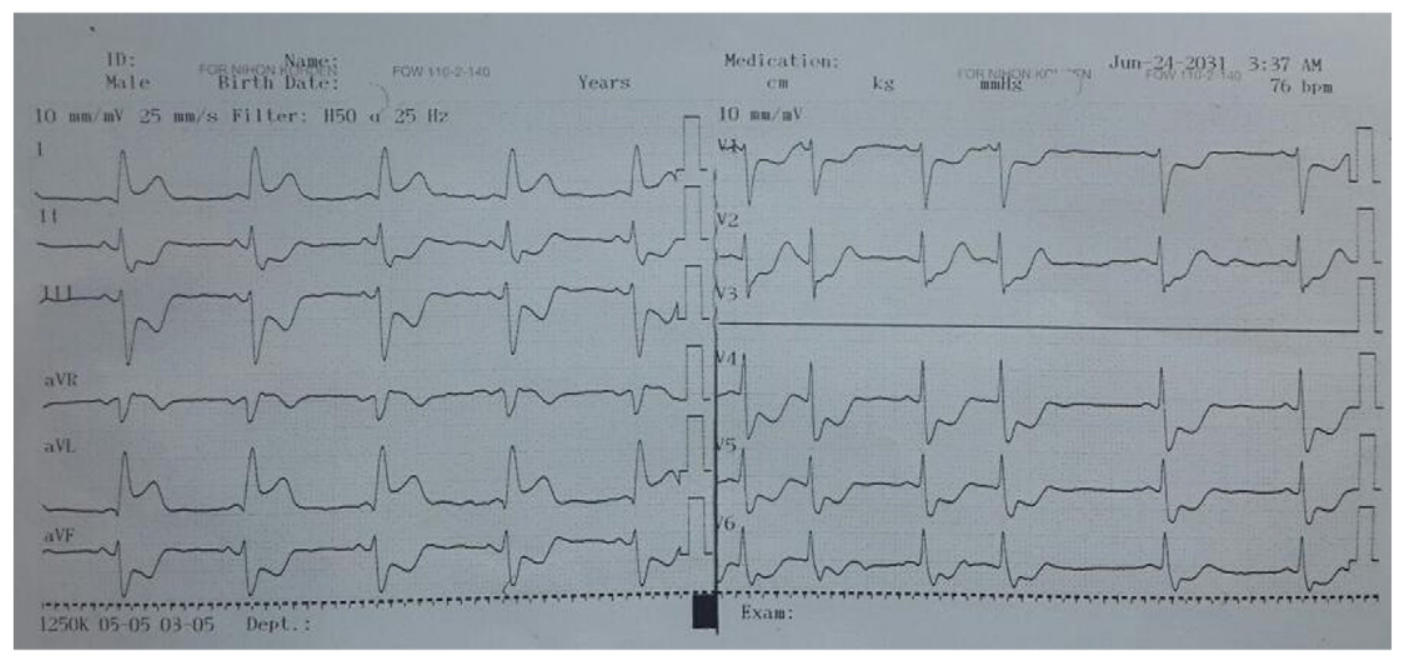

Fig. 1. ECG on admission.

For example, if the truncus originating from the right coronary truncus (R-II) has a course on the anterior of the pulmonary artery or the anterior of the right ventricle conus, it subclassifies as R-II A. If it has a course between the main pulmonary artery and the aorta, it subclassifies as R-II-B. Finally, if it continues posterior of the aortic root, it subclassifies as R-II-P. A similar subclassification scheme is available for the left single coronary artery (L-II-A, L-II-B, and L-II-P). In Class III, the single coronary artery originates from the right, $\mathrm{LAD}$, and $\mathrm{Cx}$ separately originates from the right coronary contrary to the common truncus, similar to Class II. $\mathrm{Cx}$ takes a retroaortic course to the left atrioventricular sulcus. LAD courses between the aorta and the pulmonary artery and is directed to the left interventricular sulcus. This variation is known as Type R-III. Our case was consistent with R-III. Another classification of single coronary arteries based on origin and course has been described. ${ }^{1}$

Exercise-induced acute myocardial infarction and sudden deaths have been described in cases in which the right coronary or left main coronary artery lay between the main pulmonary artery and the aorta. ${ }^{5}$ The cause is attributed to jamming of the coronary artery between two major arteries. ${ }^{5,6}$ In addition to this phenomenon, the slit-like ostium of the coronary artery could be a reason for sudden death from ischemic causes. ${ }^{5}$ Coronary anomaly can be present with subaortic or subpulmonary stenosis, ventricular septal defect, coronary artery fistula or transposition of the great arteries and tetralogy of Fallot. ${ }^{7-14}$ Horan PG et al. ${ }^{15}$ have also described a familial single coronary artery case.

Table 1

The results of biochemical laboratory tests.

\begin{tabular}{llll}
\hline Parameter & Result & Unit & Reference \\
\hline Glucose & 88 & $\mathrm{mg} / \mathrm{dL}$ & $74-106$ \\
Urea & 36 & $\mathrm{mg} / \mathrm{dL}$ & $17-49$ \\
Creatinine & 0.8 & $\mathrm{Mg} / \mathrm{dL}$ & $0.5-0.9$ \\
AST & 19 & $\mathrm{U} / \mathrm{L}$ & $0-32$ \\
ALT & 11 & $\mathrm{U} / \mathrm{L}$ & $17-49$ \\
LDH & 209 & $\mathrm{U} / \mathrm{L}$ & $135-214$ \\
Sodium & 141 & $\mathrm{mmol} / \mathrm{L}$ & $136-145$ \\
Potassium & 4.11 & $\mathrm{mmol} / \mathrm{L}$ & $3.5-5.1$ \\
Chloride & 100.7 & $\mathrm{mmol} / \mathrm{L}$ & $98-107$ \\
CK & 94 & $\mathrm{U} / \mathrm{L}$ & $20-170$ \\
CK-MB & 26 & $\mathrm{U} / \mathrm{L}$ & $<25$ \\
Troponin T & 0.043 & $\mathrm{ng} / \mathrm{mL}$ & $<0.014$ \\
WBC & $10^{\wedge} 3 / \mathrm{mm}^{3}$ & $3.9-11.7$ \\
RBC & 9.452 & $10^{\wedge} 3 / \mathrm{mm}^{3}$ & $3.85-5.16$ \\
Hb & 5.21 & $\mathrm{gr} / \mathrm{dL}$ & $12-15$ \\
Hct & 15.1 & $\mathrm{RU}$ & $34.8-45$ \\
PLT & 46.3 & $10^{\wedge} 3 / \mathrm{mm}^{3}$ & $130-400$ \\
\hline
\end{tabular}

Blood tests on admission.
Angioplasty of a case with single coronary artery includes risks due to osteal obstruction of catheters with large diameters and can result in chest pain, dyspnea, dizziness, hypotension and hemodynamic compromise. The medical team should be ready for any potential complication and they should be aware that small obstructions can cause ischemia.

In our case, LAD and CX were originated from the RCA and LAD was rudimentary. Some cases in the literature have described patients with single coronary with rudimentary LAD who had undergone $\mathrm{PCI} .{ }^{16-18} \mathrm{PCI}$ of R-III type single coronary artery patients who had a culprit lesion of circumflex artery have also been reported. ${ }^{17,19}$ Some single coronary artery patients who have acute coronary syndrome had successfully received angioplasty via the radial approach. ${ }^{20-22}$ Additionally, transcatheter aortic valve implantation with Sapien XT and CoreValve have been performed on two patients with SCA. ${ }^{23}$

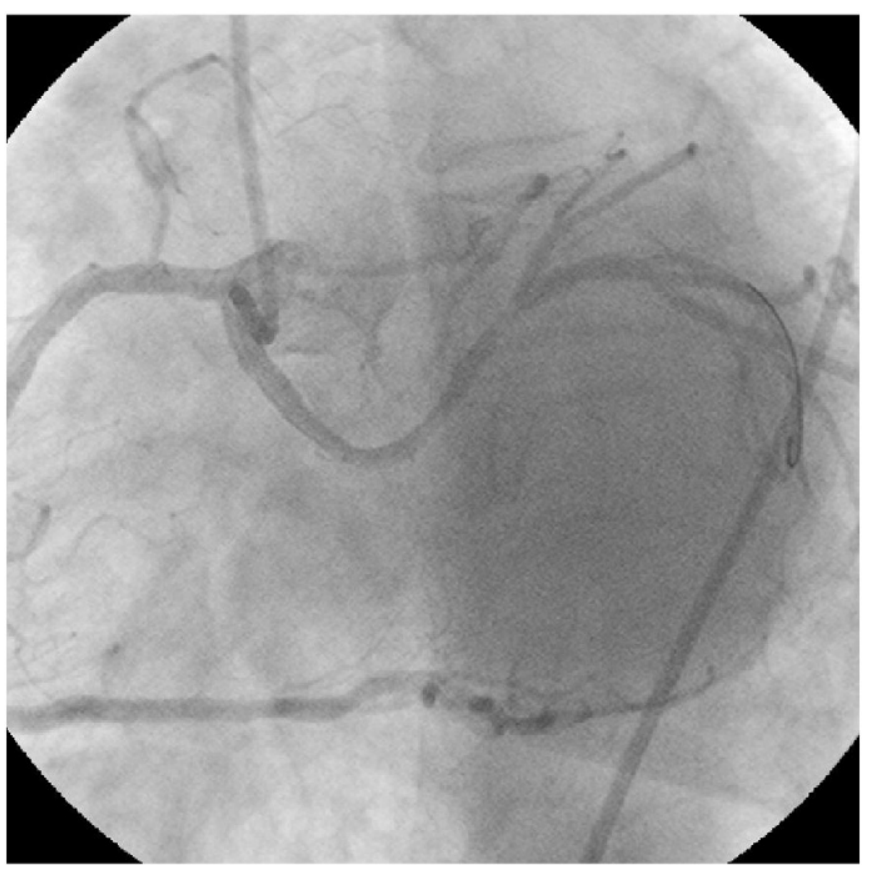

Fig. 2. Culprit lesion was on proximal $C x$. 


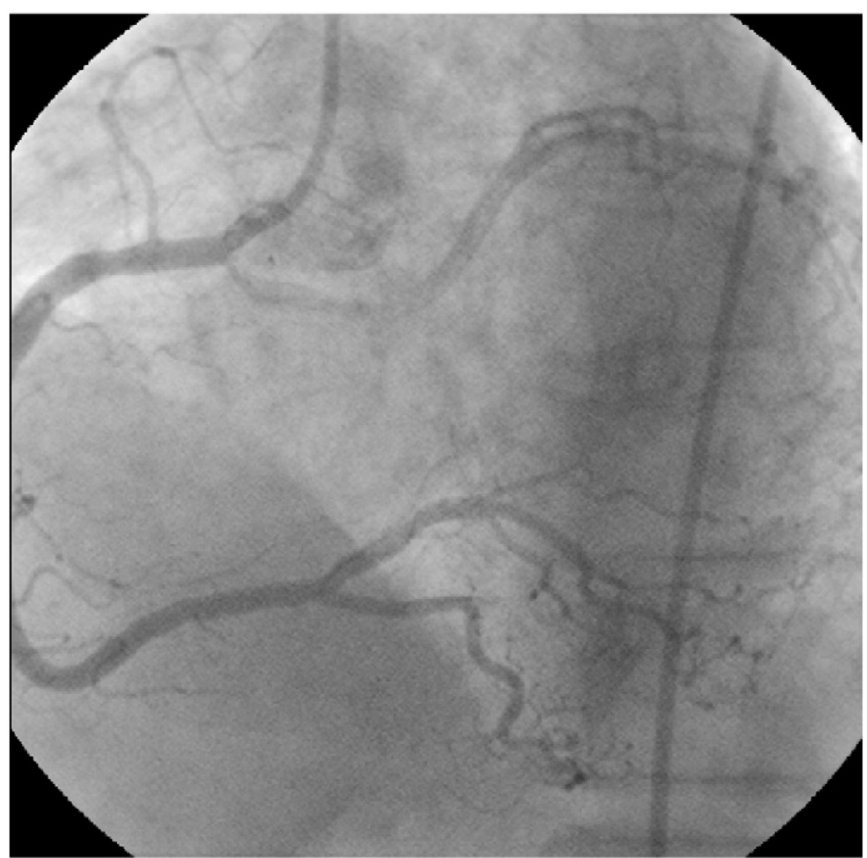

Fig. 3. Angiographic result were optimal after $\mathrm{PCI}$ of aberrant $\mathrm{Cx}$.

Table 2

Follow-up cardiac enzyme values showed early peaking values.

\begin{tabular}{llll}
\hline Parameter & On admission & 6th hour & 12th hour \\
\hline CK $(\mathrm{U} / \mathrm{L})$ & 94 & 1871 & 1832 \\
CK-MB $(\mathrm{U} / \mathrm{L})$ & 26 & 319 & 275 \\
Troponin $(\mathrm{ng} / \mathrm{mL})$ & 0.043 & 9.13 & 5.43 \\
\hline
\end{tabular}

\section{Conclusion}

The case described above is a rare instance of a patient with SCA (Lipton R-III group) with STEMI undergoing PCI to the Cx. Percutaneous coronary intervention of a single coronary artery can be difficult and susceptible to complications. Because of vessel compromise during angioplasty, this will have an impact on all three territories. ${ }^{17}$ Coronary ischemia could cause hemodynamic compromise. Operator should be aware of the potential risk of complications and the limitations of the procedure.

\section{References}

1. Shirani J, Roberts WC. Solitary coronary ostium in the aorta in the absence of other major congenital cardiovascular anomalies. J Am Coll Cardiol 1993;21:137-143.
2. Sharbaugh AH, White RS. Single coronary artery: analysis of the anatomic variation, clinical importance, and report of five cases. JAMA 1974;230:243-246.

3. Engel HJ, Torres C, Page Jr HL. Major variations in anatomical origin of the coronary arteries: angiographic observations in 4,250 patients without associated congenital heart disease. Cathet Cardiovasc Diagn 1975;1:157-169.

4. Lipton MJ, Barry WH, Obrez I, Silverman JF, Wexler L. Isolated single coronary artery: diagnosis, angiographic classification, and clinical significance. Radiology 1979;130: 39-47.

5. Roberts WC, Siegel RJ, Ziper DP. Origin of the right coronary artery from the sinus of valsalva and its functional consequences: analysis of 10 necropsy patients. Am J Cardiol 1982;49:863-868.

6. Cohen LS, Shaw LD. Fatal myocardial infarction in an 11-year-old boy associated with a unique coronary artery anomaly. Am J Cardiol 1967;19:420-423.

7. Ogden JA, Goodyear AVN. Patterns of distribution of the single coronary artery. Yale J Biol Med 1970;43:424-427.

8. Favero L, La Vecchia L, Ottani F, Martini M, Vincenzi P, Fontanelli A. Single coronary artery associated with perimembranous ventricular septal defect. Ital Heart $J$ 2003;4:813-815

9. Longenecker CG, Reemtsma K, Creech Jr O. Surgical implications of single coronary artery: a review and two case reports. Am Heart J 1961;61:382-386.

10. Kallikazaros JE, Gavaliatsis IP, Tentolouris CA. Single coronary artery associated with annuloaortic ectasia and ventricular septal defect. Cathet Cardiovasc Diagn 1990;19: 42-44.

11. Ishii M, Masuoka H, Emi Y, Mori T, Ito M, Nakano T. Ruptured aneurysm of the sinus of valsalva coexisting with ventricular septal defect and single coronary artery. Circ J 2003:67:470-472.

12. Kleinfeld M, Rozanski JJ, Brumlik JV. Situs inversus, subaortic and subpulmonic stenosis, ventricular septal defect, and single coronary artery. Chest 1976;70:391-393.

13. Cabrera A. Pilar J, Aramendi J, et al. Multiple aneurisms of the left auricula, ascending aorta and sinuses of Valsalva with interventricular communication, fibromuscular subaortic stenosis and a single coronary artery. Rev Esp Cardiol 1990;43:1-189.

14. Dhakam S, Kazmi K, Atiq M. Single coronary artery and tetralogy of Fallot. Heart 2002;87:432.

15. Horan PG, Murtagh G, McKeown PP. Single coronary artery: a familial clustering. Heart 2003;89e27.

16. Bhairrappa S, Bagi V, Subramani KS, Prasad NM. An interesting clinical scenario of patient with acute myocardial infarction with single coronary. BMJ Case Rep 2013 Feb;11:2013.

17. Ohta H, Sumiyoshi M, Suwa S, et al. Primary coronary angioplasty with stenting for acute coronary syndrome with isolated single coronary artery: a report of 2 cases. Jpn Heart J 2003;44:759-765.

18. Zhou ZJ, Kaviraj B, Cao SP, et al. Management of subacute myocardial infarction in a patient with left coronary artery originating from the right coronary artery. Nan Fang Yi Ke Da Xue Xue Bao 2011 Aug;31(8):1295-1297.

19. Sato M, Okada T, Ohara A, Aoki T, Kawamoto I. Percutaneous coronary intervention for a single coronary artery arising from the right sinus valsalva. J Cardiol 2009 Oct:54(2):322-325. http://dx.doi.org/10.1016/j.jjcc.2008.12.005 (Epub 2009 Feb 12).

20. Mahapatro AK, Patro AS, Sujatha V, Sinha SC. Isolated single coronary artery presenting as acute coronary syndrome: case report and review. Int J Angiol 2014 Jun;23(2): 143-146. http://dx.doi.org/10.1055/s-0033-1363496.

21. Kafkas N, Triantafyllou K, Babalis D. An isolated single L-I type coronary artery with severe LAD lesions treated by transradial PCI. J Invasive Cardiol 2011 Sep;23(9): E216-E218.

22. Shalganov TN. Percutaneous coronary intervention for acute myocardial infarction in a single coronary artery anomaly. Clin Cardiol 2009 Nov;32(11):E49-E51. http://dx.doi.org/10.1002/clc.20429.

23. Sorbets E, Choby M, Tchetche D. Transcatheter aortic valve implantation with either CoreValve or SAPIEN XT devices in patients with a single coronary artery. J Invasive Cardiol 2012 Jul;24(7):342-344. 